\title{
Gelsenicine from Gelsemium elegans Attenuates Neuropathic and Inflammatory Pain in Mice
}

\author{
Ming Liu, Jie Shen, Hao Liu, Ying Xu, Yan-Ping Su, Jian Yang, and Chang-Xi Yu* \\ Department of Pharmacology, College of Pharmacy, Fujian Medical University; Fuzhou, Fujian 350004, People's \\ Republic of China. Received June 23, 2011; accepted September 11, 2011
}

\begin{abstract}
Gelsemium elegans BENTH and its crude extract are widely used to treat pain in China despite its apparent toxicity. The analgesic effects of gelsenicine, an active component of $G$. elegans, however, have not been reported. The current study examined potential analgesic effects of subcutaneously injected gelsenicine using acetic acidinduced writhing, formalin-induced nociceptive behavior, and thermal hyperalgesia caused by chronic constriction injury (CCI) in mice. Gelsenicine produced dose-dependent analgesic effects in both inflammatory and neuropathic pain models. The $\mathrm{ED}_{50}$, for either the inflammatory pain $(10.4 \mu \mathrm{g} / \mathrm{kg}$ for writhing test, $7.4 \mu \mathrm{g} / \mathrm{kg}$ for formalin test) or neuropathic pain $(9.8 \mu \mathrm{g} / \mathrm{kg}$ for thermal hyperalgesia caused by CCI model), was far below the $\mathrm{LD}_{50}(95 \%$ confidence interval at $100-200 \mu \mathrm{g} / \mathrm{kg})$. Repeated subcutaneous injections of gelsenicine in CCI mice led to sustained attenuation of neuropathic pain after drug discontinuation. These results revealed that gelsenicine could be used safely to attenuate both inflammatory and neuropathic pain.
\end{abstract}

Key words Gelsemium elegans; gelsenicine; neuropathic pain; inflammatory pain; analgesia

Chronic pain is a pathological condition primarily associated with either damage or dysfunction of peripheral and central sensory pathways. ${ }^{1)}$ Despite recent efforts to understand its pathophysiology and develop new drug treatments, chronic pain remains a major challenge. Neuropathic pain, a type of chronic pain, is particularly unresponsive to currently available drugs. ${ }^{2}$

Gelsemium elegans BENTH is a toxic plant indigenous to Southeast Asia. Since ancient times, preparations of G. elegans have been widely used for medicinal purposes in China. ${ }^{3)}$ The parts of G. elegans most often used for medicinal purposes are roots, stem and/or leaves. ${ }^{3)}$ Dried and powdered root, stem, and/or leave are extensively used for the treatment of abscess, neuropathic pain, mastitis, rheumatism, wounds, ulcers, sores, leprosy and psoriasis. ${ }^{3,4}$ Methods of administration are mainly topical. The pharmacology of the extract of G. elegans is been studied increasingly. ${ }^{3)}$ According to $\mathrm{Lu},{ }^{5)} \mathrm{G}$. elegans extracts can be used to reduce pain despite its apparent toxicity. Studies in animal models have demonstrated that extracts from G. elegans have analgesic and anti-inflammatory properties. $\left.{ }^{6}\right)$ However, the clinical use of the crude extract is limited because of the narrow therapeutic window.

G. elegans extract contains many alkaloids, including gelsemine, gelsevirine, gelsenicine, and koumine. ${ }^{7-10)}$ Gelsenicine (Fig. 1) is the most toxic monomer in $G$.

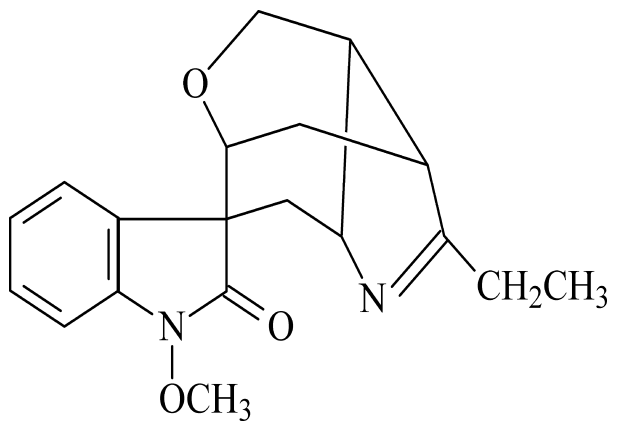

Fig. 1. Chemical Structure of Gelsenicine elegans. ${ }^{11)}$ To date, there are no reports of the analgesic effects of gelsenicine. In the current study, we examined the potential analgesic effects of gelsenicine on inflammatory and neuropathic pain in mice. The results show for the first time that gelsenicine could attenuate both neuropathic and inflammatory pain at doses far below $\mathrm{LD}_{50}$.

\section{MATERIALS AND METHODS}

Animals Male ICR mice (Shanghai Laboratory Animal Center, Chinese Academy of Sciences), weighing 18-22 g at the beginning of the experiments, were housed in groups of six and had free access to standard mouse food and water except during behavioral experiments. Mice were kept in a temperature-controlled room $\left(25 \pm 2{ }^{\circ} \mathrm{C}\right)$ with a $12 \mathrm{~h}$ light $/ 12 \mathrm{~h}$ dark cycle (lights on from 08:00 to 20:00 h). All mice were acclimatized for at least 1 week prior to the experiments. All behavioral experiments were performed between 09:00 and 17:00 h. Each mouse was used in only one experiment. The study was conducted in compliance with the international laws on animal experimentation and approved by the Committee of Ethics of Fujian Medical University.

Agents and Instruments Gelsenicine was isolated from G. elegans using one-step high-speed counter-current chromatography in our laboratory to a purity of $95.4 \%{ }^{12)}$ Test agents, including gelsenicine, aspirin (Shanghai New Asiatic Pharmaceutical, Shanghai, China), morphine hydrochloride (Northeast General Pharmaceutical Factory, Shenyang, China), acetic acid (China National Pharmaceutical Group Corporation, Beijing, China), and formalin (Shanghai Lianshi Chemical Reagent, Shanghai, China), were dissolved in sterile physiological saline $(0.9 \% \mathrm{NaCl})$. For the thermal hyperalgesia assessment, we used a Plantar Analgesia Instrument (PL-200, Chengdu Technology and Market Co., Ltd., Shandong, China).

Acute Toxicity Mice were randomly divided into six groups $(n=10)$ and received subcutaneous injection of gelsenicine $(0,0.095,0.127,0.169,0.225,0.3$, or $0.4 \mathrm{mg} / \mathrm{kg})$. Mortality and other signs of toxicity were observed and 
recorded for a period of $7 \mathrm{~d}$. The median lethal dose $\left(\mathrm{LD}_{50}\right)$ and its 95\% confidence interval were calculated with the Bliss method.

Acetic Acid-Induced Writhing Test The acetic acid-induced writhing test was performed as previously described, ${ }^{13}$ ) with minor modifications. Mice (10 per group) received subcutaneous injection of gelsenicine $(0.8,4$, or $20 \mu \mathrm{g} / \mathrm{kg})$, aspirin $(100 \mathrm{mg} / \mathrm{kg})$, or saline. Thirty minutes later, mice received an intraperitoneal injection of $0.6 \%$ acetic acid aqueous solution $(10 \mathrm{ml} / \mathrm{kg})$. The number of writhes was counted for $30 \mathrm{~min}$, starting immediately following the acetic acid injection. The inhibition of writhes was calculated as [(control mean-test mean)/control mean $] \times 100$. The analgesic effect $\left(\mathrm{ED}_{50}\right)$ was calculated using a least-square linear regression analysis of the log dose-response curves.

Formalin-Induced Nociceptive Behavior Test The formalin-induced nociceptive behavior test was based on Dubuisson and Dennis, $\left.{ }^{14}\right)$ with minor modifications. Mice were placed in a transparent plastic box for $30 \mathrm{~min}$, and then received subcutaneous injection of gelsenicine $(0.8,4$, or 20 $\mu \mathrm{g} / \mathrm{kg})$, morphine $(10 \mathrm{mg} / \mathrm{kg})$, aspirin $(100 \mathrm{mg} / \mathrm{kg})$, or saline (10 mice in each group). Thirty minutes after the drug injections, the mice were subcutaneously injected with $5 \%$ formalin $(10 \mu \mathrm{l})$ into the dorsal surface of the right hind paw. Nociceptive behavior was assessed as the time spent licking and biting and was monitored for $60 \mathrm{~min}$ in $5 \mathrm{~min}$ intervals. Nociceptive inhibition was calculated as inhibition $=100-$ $\left[\left(\right.\right.$ Time $\left._{1} \times 100\right) /$ Time $\left._{2}\right]$, where Time $_{1}$ is the mean licking time in mice receiving the test agent and $\mathrm{Time}_{2}$ is the mean licking time in the saline control group. The mean licking time refers to the mean of total time in each group, and the time can be $0-5 \mathrm{~min}$ in first phase or $15-60 \mathrm{~min}$ in second phase. The analgesic effect $\left(\mathrm{ED}_{50}\right)$ was calculated using a least-square linear regression analysis of the log doseresponse curves.

Thermal Hyperalgesia Caused by Chronic Constriction Injury (CCI) Chronic constriction injury of the sciatic nerve was used as model of neuropathic pain. The procedure followed Bennett and $\mathrm{Xie}^{15)}$ adapted to the mouse. Briefly, under pentobarbital anesthesia $(75 \mathrm{mg} / \mathrm{kg}$, intraperitoneal injection), the right sciatic nerve was exposed by blunt dissection at the mid-thigh, and loosely ligated at three sites using 5-0 chromic catgut suture (Dinghua Medical Instruments Co., Ltd., Shanghai, China). For the sham operation, the sciatic nerve was exposed but not ligated. Beginning at $3 \mathrm{~d}$ after the surgery, mice were subcutaneously injected with saline or gelsenicine $(0.8,4,20 \mu \mathrm{g} / \mathrm{kg})$ every $12 \mathrm{~h}$ for one week $(8$ 14 mice per group). Responses to thermal stimuli were examined using a method by Hargreaves et al. ${ }^{16)}$ at $1 \mathrm{~d}$ prior to the surgery (baseline), and 3, 5, 7, 9, 10,11, and $13 \mathrm{~d}$ after the surgery (at $1 \mathrm{~h}$ after subcutaneous injection of the test agent). Briefly, mice were placed in a clear plastic cage with a glass floor and allowed to acclimate for 10 to $15 \mathrm{~min}$. A beam of radiant heat was applied to the middle of the plantar surface of both CCI and contra-lateral paws. Withdrawal latency was recorded. Radiant heat was adjusted so that the baseline latency was $10-12 \mathrm{~s}$. The cutoff time was $15 \mathrm{~s}$. The latency was examined at least twice, with at least $10 \mathrm{~min}$ between two consecutive stimuli on the same paw. The hyperalgesic index (HI) of CCI is the ratio of the withdrawal latency of the CCI paw relative to that in the contra-lateral aide.
Higher HI (maximum: 1) reflects lower thermal hyperalgesia. The maximal possible effect (MPE) was calculated as $100 \times(\mathrm{HI}$ in the gelsenicine group $-\mathrm{HI}$ in the saline group $) /(1-\mathrm{HI}$ in the saline group). HI of gelsenicine and saline control groups was collected on the same day for a given animal subject. The analgesic effect $\left(\mathrm{ED}_{50}\right)$ was calculated using a least-square linear regression analysis of the $\log$ dose-response curves.

Statistical Analysis All data are presented as the mean \pm S.E.M. For the writhing and formalin test, data were analyzed with one-way analysis of variance (ANOVA), followed by Dunnett $t$-test for posthoc comparison. For thermal hyperalgesia in CCI mice, data were analyzed with two-way ANOVA (treatment $\times$ time), followed by Dunnetts $t$-test for post hoc comparison. $p$ values less than 0.05 were considered statistically significant. All analyses were performed with SPSS (version 10.0, SPSS Inc., Chicago, IL, U.S.A.).

\section{RESULTS}

LD $_{50}$ of Gelsenicine For subcutaneous injection of gelsenicine, the $95 \%$ confidence limit of the $\mathrm{LD}_{50}$ was 100 $200 \mu \mathrm{g} / \mathrm{kg}$.

Effects of Gelsenicine on Acetic Acid-Induced Writhing Gelsenicine inhibited acetic acid-induced writhing at 4 and $20 \mu \mathrm{g} / \mathrm{kg}$ (percent inhibition: $40.9 \%$ and $58.5 \%$, respectively; $p<0.05$ vs. saline control for 4, $20 \mu \mathrm{g} / \mathrm{kg}$ by one-way ANOVA followed by Dunnett $t$-test) but not at a lower dose of $0.8 \mu \mathrm{g} / \mathrm{kg}$ (Fig. 2). Percent inhibition achieved by the highest dose $(20 \mu \mathrm{g} / \mathrm{kg})$ of gelsenicine seemed to be lower than that with $100 \mathrm{mg} / \mathrm{kg}$ aspirin $(78.1 \%$ inhibition), but the difference was not statistically significant. The $\mathrm{ED}_{50}$ of subcutaneous injection of gelsenicine was $10.4 \mu \mathrm{g} / \mathrm{kg}$.

Effects of Gelsenicine on Formalin-Induced Nociceptive Behavior Subcutaneous injection of morphine (10 $\mathrm{mg} / \mathrm{kg}$ ) significantly decreased the licking and biting time in both the first phase ( $91 \%$ inhibition) ( $p<0.01 \mathrm{vs}$. saline control by one-way ANOVA followed by Dunnett $t$-test) and second phase (95\% inhibition) $(p<0.01 v s$. saline control by one-way ANOVA followed by Dunnett $t$-test). Subcutaneous injection of aspirin $(100 \mathrm{mg} / \mathrm{kg})$ significantly inhibited these behaviors, but only in the second phase ( $45 \%$ inhibition)

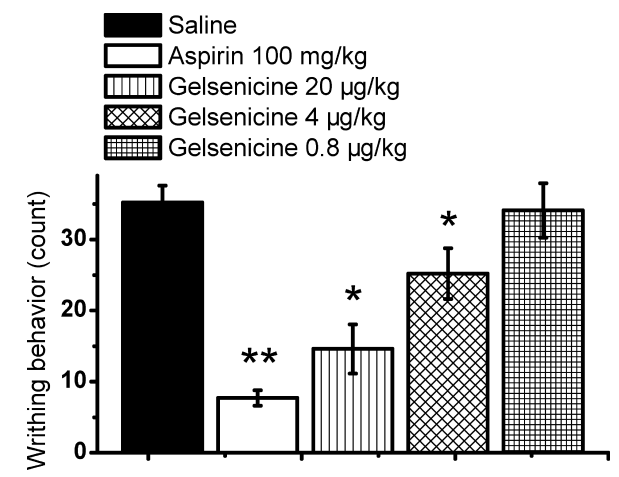

Fig. 2. Effect of Gelsenicine on Acetic Acid-Induced Writhing Behavior in Mice

Mice were treated with aspirin or gelsenicine at $30 \mathrm{~min}$ prior to intraperitoneal injection of $0.6 \%$ acetic acid $(10 \mathrm{ml} / \mathrm{kg})$. The writhing behavior was monitored for $30 \mathrm{~min}$ after acetic acid. $n=10 . * p<0.05, * * p<0.01 v$ s. saline control. 
$(p<0.05 v s$. saline control by one-way ANOVA followed by Dunnett $t$-test). Subcutaneous injection of gelsenicine dosedependently inhibited the nociceptive behavior only in the second phase, with $29 \%$ inhibition at $0.8 \mu \mathrm{g} / \mathrm{kg}, 43 \%$ inhibition at $4 \mu \mathrm{g} / \mathrm{kg}$ and $59 \%$ inhibition at $20 \mu \mathrm{g} / \mathrm{kg}(p<0.05 v s$. saline control for $0.8 \mu \mathrm{g} / \mathrm{kg} ; p<0.01 v s$. saline control for 4 , $20 \mu \mathrm{g} / \mathrm{kg}$ by one-way ANOVA followed by Dunnetts $t$-test) (Fig. 3). The $\mathrm{ED}_{50}$ of gelsenicine was $7.4 \mu \mathrm{g} / \mathrm{kg}$.

Effects of Gelsenicine on Thermal Hyperalgesia Caused by CCI CCI produced significant thermal hyperalgesia for the entire duration of experiment $(p<0.01 v s$. sham control by two-way ANOVA followed by Dunnetts $t$-test, Fig. 4). Gelsenicine attenuated thermal hypersensitivity at $0.8,4$, $20 \mu \mathrm{g} / \mathrm{kg}(p<0.05 v s$. saline control for $0.8 \mu \mathrm{g} / \mathrm{kg} ; p<0.01$ $v s$. saline control for $4,20 \mu \mathrm{g} / \mathrm{kg}$ by two-way ANOVA followed by Dunnetts $t$-test, Fig. 4). Gelsenicine treatment was discontinued on day 9 , but the effect on thermal hyperalgesia was still apparent on day 10 (Fig. 4). HI was 0.84 and 0.86 on day 9 in mice receiving 4 and $20 \mu \mathrm{g} / \mathrm{kg}$ gelsenicine,

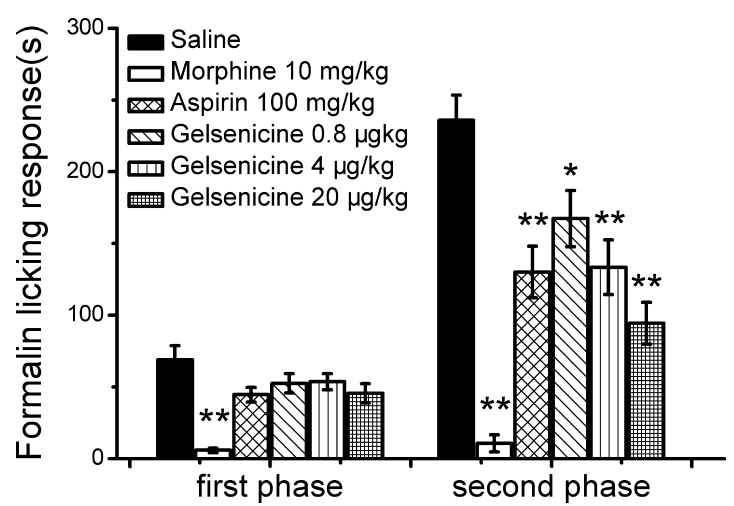

Fig. 3. Effect of Gelsenicine on Formalin-Induced Nociceptive Behavior in Mice

Mice were treated with morphine $(10 \mathrm{mg} / \mathrm{kg})$, aspirin $(100 \mathrm{mg} / \mathrm{kg})$, gelsenicine $(0.8$, 4 , or $20 \mu \mathrm{g} / \mathrm{kg}$ ), or saline at $30 \mathrm{~min}$ prior to subcutaneous injection of $5 \%$ formalin $(10 \mu 1)$ into the dorsal surface of the right hind paw. The number of formalin licking responses was measured in the first phase $(0-5 \mathrm{~min}$ post-injection $)$ and the second phase (15 - 60 min post-injection). $n=10 . * p<0.05, * * p<0.01 v s$. saline control.

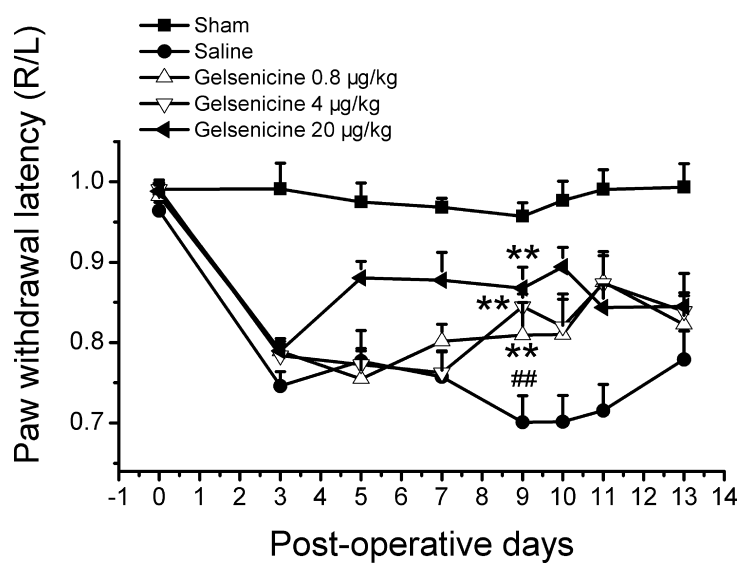

Fig. 4. Effects of Repeated Gelsenicine Treatment on Thermal Hyperalgesia Induced by CCI in Mice

The right sciatic nerve was loosely ligated at three sites using 5-0 chromic catgut suture under anesthesia. Beginning at $3 \mathrm{~d}$ after the surgery, mice were subcutaneously injected with saline or gelsenicine $(0.8,4,20 \mu \mathrm{g} / \mathrm{kg})$ every $12 \mathrm{~h}$ for one week $(7-15$ mice per group). Responses to thermal stimuli were examined at $1 \mathrm{~d}$ prior to the surgery (baseline), and 3, 5, 7, 9,10,11, and $13 \mathrm{~d}$ after the surgery (at $1 \mathrm{~h}$ after subcutaneous injection of the test agent). \#p<0.01 vs. sham group; $* * p<0.01 v s$. saline control in mice subjected to CCI, two-way ANOVA with post hoc Dunnetts $t$-test. respectively. On day 10 , $\mathrm{HI}$ in mice receiving $20 \mu \mathrm{g} / \mathrm{kg}$ gelsenicine was 0.89 . Based on the data collected on day 9, the $\mathrm{ED}_{50}$ of gelsenicine was $9.8 \mu \mathrm{g} / \mathrm{kg}$.

\section{DISCUSSION}

The $\mathrm{LD}_{50}$ of gelsenicine upon subcutaneous injection was similar to that previously reported for intraperitoneal injection. ${ }^{11)}$ The toxicity profiles, including decreased motor activity, decreased respiratory rate, coarse body tremors and violent convulsions, were as also similar to previously described. ${ }^{6}$

We employed three standard tests to evaluate potential analgesic effects of gelsenicine. Acetic acid-induced writhing is useful for evaluation of nonsteroidal, anti-inflammatory compounds and widely used for detecting both central and peripheral analgesia. ${ }^{17-19)}$ Prostaglandin biosynthesis plays an important role in nociception under this model. ${ }^{20)}$ In the current study, gelsenicine produced significant analgesic effect at relatively high doses of 2 and $10 \mu \mathrm{g} / \mathrm{kg}$, thus suggesting a peripheral mechanism. In addition to prostaglandins, several other inflammatory mediators, including sympathomimetic amines, tumour necrosis factor- $\alpha$ (TNF$\alpha$ ), interleukin- $\beta$ (IL-1 $\beta$ ) and interleukin-8 (IL-8), have been reported to be associated with the nociceptive response to acetic acid in mice. ${ }^{13,21,22)}$ Ribeiro et al. ${ }^{13)}$ showed that writhing response induced by acetic acid is highly dependent on both peritoneal macrophages and mast cells. Future studies are needed to clarify the potential contribution of these additional mechanisms to the action of gelsenicine in the writhing model.

Formalin produces pain in a biphasic manner. ${ }^{23)}$ The first transient phase is ascribed to the direct effect of formalin on sensory C fibers, whereas the second prolonged phase is caused mainly by inflammation. ${ }^{24,25)}$ Drugs that act primarily as central analgesics could inhibit both phases while peripherally acting drugs inhibit only the second phase. ${ }^{26}$ Substance $\mathrm{P}$ and bradykinin participate in the first phase, whereas histamine, serotonin, prostaglandin and bradykinin are involved in the second-phase responses. ${ }^{24)}$ The fact that gelsenicine suppressed nociception in the second phases but not in the first phase of the formalin test, indicated that the action of gelsenicine is mediated mainly through a peripheral mechanism.

CCI model is the most widely used animal model for neuropathic pain. ${ }^{15,27-29)}$ One of the core features in neuropathic pain is thermal hyperalgesia. ${ }^{30,31)}$ Consistent with previous results, ${ }^{32}$ we observed that all CCI mice exhibited thermal hyperalgesia within $2-3 \mathrm{~d}$ after surgery. Repeated gelsenicine treatment at doses far below its $\mathrm{LD}_{50}$ produced a dose-dependent analgesic effect. Neuropathic pain is dependent upon sensitization by constant stimulation via the afferent neural pathways, which may arise from the injured peripheral nerve itself or changes in the dorsal root ganglia, e.g., sympathetic sprouting. ${ }^{33)}$ It is possible that gelsenicine suppresses this source of ectopic input by modifying the neuroinflammatory activity at the site of nerve injury and by promoting the nerve regenerative process. One possibility is that gelsenicine enhances myelin repair indirectly by inhibiting the inflammatory response that contributes to fiber damage. Alternatively, gelsenicine may promote remyelination 
through modulation of neurotrophic factors. The effect of gelsenicine on pain-related behaviour could also be mediated by down-regulation of TNF- $\alpha$, since this cytokine has been reported to play a pivotal role in the initiation and maintenance of neuropathic pain. ${ }^{34,35)}$ The use of endogenously or synthetically produced anti-inflammatory cytokines ${ }^{36)}$ or antibodies against TNF- $\alpha$ or its receptors, as well as the use of TNF- $\alpha$ antagonists or synthesis inhibitors such as thalidomide attenuate the hyperalgesia following $\mathrm{CCI} .{ }^{37-39)}$

An attempt to extrapolate our findings using a body surface area (BSA) normalization method ${ }^{40}$ yielded theoretical $\mathrm{ED}_{50}$ of $36-50.6 \mu \mathrm{g}$ for inflammatory pain and $47.7 \mu \mathrm{g}$ for neuropathic pain in human subjects weighing $60 \mathrm{~kg}$. Such doses are lower than the amount of gelsenicine $(\approx 130 \mu \mathrm{g})$ included in preparations containing $G$. elegans extract ${ }^{4,12}$ for human treatment.

In conclusion, our results demonstrated for the first time that gelsenicine could attenuate both inflammatory and neuropathic pain at doses far below $\mathrm{LD}_{50}$. Gelsenicine may represent a new therapy for inflammatory and neuropathic pain.

Acknowledgements This work was supported by the National Natural Science Foundation of China (No. 30973520), the Natural Science Foundation of Fujian Province of China (No. 2009J01156), the Exploitation Program of Industrial Technology of Fujian Development and Reform Commission of China ([2009] No. 958), and the Key Program of Scientific Research of Fujian Medical University (No. ZD009).

\section{REFERENCES}

1) Kuner R., Nat. Med., 16, 1258-1266 (2010).

2) Mizoguchi H., Watanabe C., Yonezawa A., Sakurada S., Int. Rev. Neurobiol., 85, 249-260 (2009).

3) Zhang L., Lin J., Wu Z., J. Chin. Med. Mater., 26, $451-453$ (2003).

4) Chen Z. L., J. Nav. Med., 2, 52-53 (1984).

5) Lu W. G., Chin. J. Mod. Appl. Pharm., 8, 11-13 (1991).

6) Rujjanawate C., Kanjanapothi D., Panthong A., J. Ethnopharmacol., 89, 91-95 (2003).

7) Lin L. Z., Cordell G. A., Ni C. Z., Clardy J., Phytochemistry, 29, 965-968 (1990).

8) Lin L. Z., Cordell G. A., Ni C. Z., Clardy J., Phytochemistry, 30, $1311-1315$ (1991).
9) Lin L. Z., Hu S. F., Cordell G. A., Phytochemistry, 43, 723-726 (1996).

10) Lin L. Z., Cordell G. A., Zhou N. C., Clardy J., Phytochemistry, 29, 3013-3017 (1990).

11) Du X. B., Dai Y. H., Zhang C. L., Lu S. L., Liu Z. G., Acta Chim. Sin., 40, 1137-1141 (1982).

12) Shen J., Su Y. P., Xu Y., Liu H., Liu M., Yu C. X., Chin. Tradit. Herbal Drugs, 40, 1392-1395 (2009).

13) Ribeiro R. A., Vale M. L., Thomazzi S. M., Paschoalato A. B., Poole S., Ferreira S. H., Cunha F. Q., Eur. J. Pharmacol., 387, 111-118 (2000).

14) Dubuisson D., Dennis S. G., Pain, 4, 161-174 (1977).

15) Bennett G. J., Xie Y. K., Pain, 33, 87-107 (1988).

16) Hargreaves K., Dubner R., Brown F., Flores C., Joris J., Pain, 32, $77-$ 88 (1988).

17) Fukawa K., Kawano O., Hibi M., Misaki N., Ohba S., Hatanaka Y., J. Pharmacol. Methods, 4, 251-259 (1980).

18) Ferreira S., Vane J., Annu. Rev. Pharmacol., 14, 57-73 (1974).

19) Berkenkopf J. W., Weichman B. M., Prostaglandins, 36, 693-709 (1988).

20) Zeilhofer H. U., Brune K., Trends Pharmacol. Sci., 27, 467-474 (2006).

21) Duarte I. D., Nakamura M., Ferreira S. H., Braz. J. Med. Biol. Res., 21, $341-343$ (1988).

22) Ribeiro R. A., Vale M. L., Ferreira S. H., Cunha F. Q., Eur. J. Pharmacol., 391, 97-103 (2000).

23) Wheeler-Aceto H., Cowan A., Agents Actions, 34, 264-269 (1991).

24) Shibata M., Ohkubo T., Takahashi H., Inoki R., Pain, 38, 347-352 (1989).

25) Hunskaar S., Hole K., Pain, 30, 103-114 (1987).

26) Rosland J. H., Tjølsen A., Maehle B., Hole K., Pain, 42, 235-242 (1990).

27) Nahin R. L., Ren K., De León M., Ruda M., Pain, 58, 95-108 (1994).

28) Miki K., Fukuoka T., Tokunaga A., Noguchi K., Neuroscience, 82, $1243-1252$ (1998)

29) Kajander K. C., Bennett G. J., J. Neurophysiol., 68, 734-744 (1992)

30) Ueda H., Pharmacol. Ther., 109, 57-77 (2006).

31) Campbell J. N., Meyer R. A., Neuron, 52, 77—92 (2006).

32) Backonja M., Wang B., Miletic V., Brain Res., 639, 337-340 (1994).

33) Garcia-Larrea L., Magnin M., Presse Med., 37, 315-340 (2008).

34) Sommer C., Schmidt C., George A., Exp. Neurol., 151, 138-142 (1998).

35) Sommer C., Schäfers M., Brain Res., 784, 154-162 (1998).

36) Wagner R., Janjigian M., Myers R. R., Pain, 74, 35- 42 (1998).

37) Sommer C., Schäfers M., Marziniak M., Toyka K. V., J. Peripher. Nerv. Syst., 6, 67-72 (2001).

38) Sommer C., Marziniak M., Myers R. R., Pain, 74, 83-91 (1998)

39) Sommer C., Lindenlaub T., Teuteberg P., Schäfers M., Hartung T., Toyka K. V., Brain Res., 913, 86-89 (2001).

40) Reagan-Shaw S., Nihal M., Ahmad N., FASEB J., 22, 659-661 (2008). 